\title{
REVIEW
}

\section{Developmental changes in hematopoietic stem cell properties}

\author{
Michael R Copley ${ }^{1}$ and Connie J Eaves ${ }^{1,2}$ \\ Hematopoietic stem cells (HSCs) comprise a rare population of cells that can regenerate and maintain lifelong blood cell \\ production. This functionality is achieved through their ability to undergo many divisions without activating a poised, but latent, \\ capacity for differentiation into multiple blood cell types. Throughout life, HSCs undergo sequential changes in several key \\ properties. These affect mechanisms that regulate the self-renewal, turnover and differentiation of HSCs as well as the \\ properties of the committed progenitors and terminally differentiated cells derived from them. Recent findings point to the \\ Lin28b-let-7 pathway as a master regulator of many of these changes with important implications for the clinical use of HSCs \\ for marrow rescue and gene therapy, as well as furthering our understanding of the different pathogenesis of childhood and \\ adult-onset leukemia. \\ Experimental \& Molecular Medicine (2013) 45, e55; doi:10.1038/emm.2013.98; published online 15 November 2013
}

Keywords: hematopoietic stem cells; HMGA2; Lin28-let7 pathway; ontogeny; self-renewal

\section{INTRODUCTION}

The mammalian hematopoietic system produces a collection of morphologically and functionally diverse mature cell types, which together perform key physiological processes including solute and $\mathrm{O}_{2}$ transport, immunity and hemostasis. All of these mature blood cells are ultimately derived by a continuous, multi-step process of lineage restriction and activation of specific differentiation programs in rare self-maintaining hematopoietic stem cells (HSCs). ${ }^{1}$

Much progress has been made recently in identifying cellsurface markers that correlate closely with the possession of HSC functionality, thus permitting the isolation of HSCs from human and mouse sources at very high purities (10-50\%). ${ }^{2}$ These advances, augmented by gene knockout studies, have allowed the identification of many genes that are required for HSCs to be generated and/or maintained at normal levels. ${ }^{3}$ Nevertheless, a molecular or phenotypic signature that permits the direct, specific and sensitive detection of HSCs remains elusive. Thus, the measurement and characterization of HSCs continues to rely on clonal tracking methods that use retrospective approaches to detect the ability of single input cells to produce mature short-lived blood cells in vivo for prolonged periods. ${ }^{4}$ The durability of this output potential and the demonstration of an accompanying ability to produce undifferentiated progeny with the same long-term blood cell producing capacity, is now recognized to be a key aspect of the definition of HSCs. This is particularly critical given the extensive but inevitably constrained self-maintaining ability of other types of long-term multipotent hematopoietic cells that can be prospectively isolated and shown to have different molecular features. ${ }^{5-7}$

An intriguing feature of HSCs is their high degree of heterogeneity. ${ }^{8}$ A long recognized source of such variability in HSC properties is their developmental stage. This has been historically apparent in comparisons of hematopoietic cells present in fetal and adult tissues, ${ }^{9-11}$ but also found to continue into old age. ${ }^{12}$ Early evidence of differences between the biological properties of primitive hematopoietic cells from fetal and adult tissues were revealed from investigations of mouse hematopoietic cells that form macroscopically visible clones of differentiating blood cells in the spleen of irradiated mice injected 9-14 days previously. ${ }^{13}$ These so-called colonyforming units-spleen (CFU-S) were initially thought to detect a fraction of HSCs that colonize the spleen because they could generate all myeloid cell types (erythroid, megakaroyopoietic and granulopoietic) as well as progeny CFU-S with similar potentialities demonstrable in secondary transplants. ${ }^{14,15}$ However, it is now known that most CFU-S do not overlap

\footnotetext{
${ }^{1}$ Terry Fox Laboratory, BC Cancer Agency, Vancouver, BC, Canada and ${ }^{2}$ Departments of Medical Genetics and Medicine, University of British Columbia, Vancouver, BC, Canada

Correspondence: Dr CJ Eaves, Terry Fox Laboratory, BC Cancer Agency, 675 West 10th Avenue, Vancouver, BC, Canada V5Z 1L3.

E-mail: ceaves@bccrc.ca
}

Received 16 July 2013; accepted 29 July 2013 
with HSCs that possess lifelong repopulating ability. Rather, they represent a type of multipotent, transient amplifying cell. ${ }^{16,17}$ Nevertheless, the quantitative nature of the CFU-S assay made it possible to demonstrate the high cycling activity of fetal CFU-S, which contrasts with the very low cycling activity characteristic of CFU-S in the unperturbed adult. ${ }^{9}$ Similarly, the rate and ultimate level of regeneration of CFU-S from mouse fetal liver (FL) cells transplanted into irradiated recipients was found to be much greater than that obtained from a comparable transplant of adult bone marrow (BM) cells. ${ }^{10}$ More recently, evidence of a similar superiority in the regenerative pace and output of human FL and adult BM transplants in irradiated immunodeficient (NOD/SCID) mice has been noted. ${ }^{18,19}$

In this review, we summarize salient examples of differences in the properties of fetal and adult hematopoietic cells with a particular focus on those that affect or are initiated within the HSC compartment. We also discuss recent findings pertinent to understanding the underlying molecular mechanisms regulating these changes.

\section{ORIGIN OF HSCS}

HSCs arise in different sites and change their site of activity during development

The first hematopoietic cells to be produced during embryogenesis are nucleated erythrocytes and macrophages. These cells appear within the extra-embryonic blood islands of the yolk sac between embryonic day 7-7.5 in the mouse $\mathrm{e}^{20}$ and around day 18 of gestation in humans. ${ }^{21}$ Soon after, erythroid, granulopoietic and multipotent progenitors with in vitro clonogenic activity and limited in vivo repopulating activity appear, but all before cells with long-term transplantable HSC activity can be detected. ${ }^{18,22,23}$ In both species, current evidence suggests that the latter arise within the aorta-gonado-mesonephros region of the embryo proper, at E10.5 $5^{24-27}$ in mice and after 5-6 weeks of gestation in humans. ${ }^{23,28}$ Subsequently, HSCs can also be found in other tissues including the placenta ${ }^{29-31}$ as well as the FL. ${ }^{32}$ There is some evidence that HSCs may arise independently in the yolk $\mathrm{sac}^{33}$ and placenta ${ }^{30}$ but those found in the FL are thought to be derived entirely from HSCs that originate elsewhere. ${ }^{34,35}$ HSCs then expand rapidly in the FL, which becomes the major site of hematopoiesis until birth. ${ }^{11,25,36,37}$ Colonization of the BM begins in the mouse on E17 and in both species, the BM becomes the major hematopoietic organ soon after birth and throughout adulthood. ${ }^{38}$

Given the importance of environmental signals in eliciting responses to changing body needs for different blood cell types throughout the growth of the embryo and after birth, it seems likely that the activity of HSCs (and their differentiating progeny) is influenced by the dramatic changes in their locations that take place during this period. Although the role of such extrinsic factors have been difficult to interrogate, evidence of intrinsic changes have been easier to infer from comparisons of their behaviour when assessed in the same environment either in vitro or in vivo (that is, after transplantation into adult-irradiated recipients).

\section{Do adult HSCs arise from their fetal counterparts?}

A fundamental question pertaining to the developmental origin of HSCs is the extent to which adult BM HSCs are lineally related to those that first appear in the embryo. The strongest evidence supporting this lineal relationship comes from studies using inducible recombination-based marking strategies. The first of these studies made use of floxed yellow fluorescent protein transgenic mice that express a tamoxifeninducible Cre-ER ${ }^{\mathrm{T}}$ recombinase under the control of the stem cell enhancer of the $S c l$ gene (which encodes a transcription factor required for the establishment of hematopoiesis). ${ }^{39,40}$ When recombination was induced at E10.5 and E11.5 by tamoxifen injections, $17 \%$ of the $\mathrm{Lin}^{-} \mathrm{Sca}^{+} \mathrm{Kit}^{+}$cells became yellow fluorescent protein plus at E14.5 and subsequent transplantation of these marked cells into irradiated adult recipients resulted in an $8-10 \%$ contribution of their yellow fluorescent protein plus progeny to the donor-derived hematopoietic cells detected 5 months post transplant-directly demonstrating the derivation of adult HSCs from fetal cells that express Scl. Notably, the contribution of E10.5/E11.5 marked cells to adult hematopoiesis was far from complete. Thus some adult HSCs may be derived later in development in a de novo fashion or from fetal cells expressing $S c l$ that are not HSCs, or from fetal HSCs in which Cre is not successfully activated. Using a similar approach, but instead employing a Runx1-dependent marking system, it has been shown that E7.5 Runx1-expressing cells, which are presumably primitive precursors of erythrocytes, give rise to a significant proportion of fetal and adult hematopoietic cells. ${ }^{41}$ Evidence of a linear relationship between fetal and adult hematopoietic cells is further provided by the finding that single transplanted E14.5 FL HSCs, can give rise to long-term stable hematopoiesis following their transplantation into adult recipients, a property that would not be expected if fetal HSCs had only transient output capacities. ${ }^{7}$

\section{Early developmental changes manifested in the differentiating progeny of HSCs}

The erythroid lineage. The primitive erythrocytes that appear first in the developing mammalian embryo are a transient population distinguished from the later definitive erythrocytes in their retention of a nucleus, expression of embryonic globin genes and exclusive origin from the yolk sac. ${ }^{42}$ In contrast to this primitive-to-definitive erythrocyte switch that occurs in all mammals, a second type of hemoglobin switching, referred to as the fetal-to-adult switch, occurs exclusively in humans and old world monkeys. This latter transition involves a change from $\gamma$ - to $\beta$-globin gene expression and is initiated in the mid-gestation fetus and completed within the first year after birth. It is thought to facilitate increased oxygen scavenging from maternal blood, as the HbF molecule $\left(\alpha_{2} \gamma_{2}\right)$ has a higher oxygen affinity than the adult-type hemoglobin $\left(\alpha_{2} \beta_{2}\right)$.

Differences between fetal and adult erythroid-restricted progenitors (colony-forming unit erythroid; CFU-E) in the mouse have also been reported. For example, fetal CFU-E are more sensitive to erythropoietin as shown by erythropoietin 
dose-response analyses of their ability to express their clonogenic potential in vitro. ${ }^{43}$ The change in erythropoietin sensitivity of CFU-E was reported to occur gradually between fetal and adult life. ${ }^{44}$

Megakaryocyte progenitors. In the BM of adult humans, many megakaryocytes undergo multiple endomitotic divisions to produce large cells of high ploidy before platelets are released from them by a process of fragmentation of their cytoplasm. In contrast, the megakaryocytes produced in human fetal hematopoietic tissues initiate a similar process of platelet release when the cells are smaller and lower ploidy but at an equivalent stage of cytoplasmic maturity. ${ }^{45-48}$ Interestingly, this difference is replicated in vitro when the outputs of clonogenic precursors of megakaryocytes present in human umbilical cord blood (CB) and mobilized adult peripheral blood are compared, suggesting the operation of an underlying cell-intrinsic mechanism. ${ }^{49,50}$

Granulopoietic cells. Human FL monocytic cells are distinct from their adult counterparts with respect to their ability to differentiate directly from a $\mathrm{CD} 14^{\text {low }} \mathrm{CD} 16^{-}$precursor to $\mathrm{CD} 14^{\text {high }} \mathrm{CD} 16^{+}$cells, without producing a $\mathrm{CD} 14^{\text {high }} \mathrm{CD} 16^{-}$ intermediate. ${ }^{51}$ Fetal monocytic cells also differ from adult monocytes in their display of properties characteristic of adult M2 macrophages, including increased expression of chemokines, scavenger receptors and tissue-degrading enzymes. ${ }^{51}$

Lymphopoiesis. It was first demonstrated in 1985 that a subset of mouse B-cells, called B-2 B-cells, can be produced upon transplantation of either neonatal liver or adult BM; however, another subset, called B-1 B-cells, can be efficiently generated only by transplants of neonatal liver. ${ }^{52}$ More recently, it was shown that this difference applies specifically to B-1a cells. Emerging evidence also suggests that splenic marginal zone B-cells are of uniquely fetal origin, ${ }^{53,54}$ a notion that is supported by a recent report of a marginal zonerestricted embryonic progenitor. ${ }^{55}$

During mouse development, the first $\mathrm{CD} 4{ }^{-} \mathrm{CD} 8{ }^{-}$cells that appear in the thymus express the $\mathrm{V} \gamma 3 \mathrm{~V} \delta 1 \mathrm{~T}$-cell receptor, followed by a second wave of T-cell receptor $\mathrm{V} \gamma 4 \mathrm{~V} \delta 1$ cells. ${ }^{56,57}$ Like B-1a B-cells, the production of these fetal-type T-cells is assumed to be mediated at the HSC level, as adult HSCs produce only $\mathrm{V} \gamma 2, \mathrm{~V} \gamma 5$ and T-cell receptor $\alpha \beta$ T-cells. ${ }^{57}$ Similarly, invariant natural killer $\mathrm{T}$ cells are only produced during a short developmental window, with a peak at 2 weeks after birth in mice. ${ }^{58,59}$ Recent evidence suggests that this phenomenon is a consequence of a higher invariant natural killer $\mathrm{T}$ cell potential for neonatal double positive $\left(\mathrm{CD} 4{ }^{+} \mathrm{CD} 8{ }^{+}\right)$thymocytes. ${ }^{60}$

\section{Developmental changes in the properties of HSCs}

Lineage output potentialities. Historically, HSCs have been assumed to be primed epigenetically to generate all blood cell lineages with equal probabilities, the heterogeneity in observed mature cell outputs being determined by poorly understood stochastic events. ${ }^{5-7,61,62}$ Indeed, in textbook descriptions of
HSCs, self-renewal of multi-potency is typically the key defining phraseology used. In addition, evidence exists for self-amplifying and cross-suppressive transcription factormediated mechanisms of 'commitment' leading to the ultimate activation of singular differentiation 'programs' within initially multipotent cells, Pu.1 and Gatal being the classic examples. ${ }^{63}$ The more recent discovery of selfperpetuating unique patterns of differentiation in serially transplanted clones derived from single mouse HSCs, and a change in their relative prevalence during ontogeny/aging, was thus unanticipated. $5,7,64$

We have introduced the terms: $\alpha$-, $\beta$-, $\gamma$ - and $\delta$-HSCs to distinguish four subsets of mouse HSCs based on their relative individual contributions to the myeloid (granulocyte-monocyte) as compared with the lymphoid $(\mathrm{B}+\mathrm{T})$ cells present in the peripheral blood 16 weeks post-transplant. ${ }^{5}$ The $\alpha$-HSCs and $\beta$-HSCs are of particular interest because both of these subsets are uniquely and equivalently endowed with durable self-renewal ability (serial transplantability). All four subtypes are present in the mouse FL, however, the lymphoid-deficient $\alpha$-HSCs are barely detectable in contrast to the prevalent $\beta$-HSCs. In contrast, adult BM contains approximately half as many $\alpha$-HSCs as $\beta$-HSCs. Interestingly, by 3 weeks of age, the $\alpha$-HSC content of the BM is already very similar to that of the adult BM. However, this developmental increase in the proportion of $\alpha$-HSCs does not appear to be intrinsically determined, as an adult-like distribution of their numbers is seen in the newly colonized E18.5 BM, even though the distribution in the FL is the same as at E14.5. ${ }^{7}$ These findings suggest that the BM microenvironment, as compared with that of the FL, is more stimulatory of $\alpha$ - versus $\beta$-HSC expansion, or selectively favors seeding of the BM with $\alpha$ - as compared with $\beta$-HSCs.

Transplants of FL HSCs produce, on average, an $\sim$ twofold higher contribution of granulocytes and monocytes (Ly6g ${ }^{+}$ and/or $\mathrm{Macl}^{+}$) to their total leukocyte progeny, as compared with adult BM HSCs. ${ }^{65}$ Intriguingly, this higher myeloid output of fetal mouse HSCs switches to an adult pattern between 3 and 4 weeks of age and also appears to be mediated at the HSC level, as shown by serial transplant experiments. ${ }^{65}$

Proliferative activity. HSCs in fetal tissues show the same high cycling activity as CFU-S and, similarly, become a largely quiescent population in the adult (changing from an estimated fraction of cycling cells of close to $100 \%$ in the E14.5 FL of mice to $\sim 10 \%$ in adult $\left.\mathrm{BM}^{66-68}\right)$. Interestingly, the cycling status of HSCs in mice appears to be site-independent as it remains unchanged as the HSCs move from the FL to the BM until 3 weeks after birth when it is abruptly altered within a 1week period. ${ }^{65,68}$ These features again point strongly to an intrinsically determined mechanism. In humans, an analogous change in HSC turnover rate is inferred from the abrupt change in the rate of leukocyte telomere shortening that appears to occur between 1 and 3 years after birth, ${ }^{69,70}$ and more clearly evident between 1 and 2 years after birth in individually tracked baboons. ${ }^{71}$ A recent study suggests that a 
developmentally regulated decrease in expression of the transcription factor, $\mathrm{C} / \mathrm{EBPa}$, is responsible for this in vivo switch in HSC cycling activity in the mouse. ${ }^{72}$

A number of cell-surface markers and dye-efflux phenotypes used to isolate HSCs from adult mouse BM, show an altered pattern of expression when cycling HSCs are studied (for example, fetal mouse HSCs or stimulated adult mouse BM HSCs) ${ }^{73}$ As a result, different phenotypes had to be used to enable fetal and adult HSCs to be isolated at high purities. ${ }^{65,74}$ More recently, new mouse HSC markers have been discovered that are not affected by the cycling status or different developmental origin of the HSCs. ${ }^{73}$ Their use allows mouse HSCs to be isolated at near purity from every in vivo source thus far studied ${ }^{6,7,75}$ thereby bypassing many caveats in historical comparisons of HSCs purified using different phenotypes.

HSC self-renewal. In mice, it has been shown that E14.5 FL HSCs differ from adult BM HSCs in the rate at which they regenerate hematopoiesis, including their own numbers, in transplanted irradiated recipients. ${ }^{11,65,67,76,77}$ This difference is thought to be at least partly due to a greater in vivo selfrenewal of the FL HSCs, as their superior regenerative activity is seen regardless of the number of HSCs initially transplanted (over a 100-fold range of 10-1000). ${ }^{78}$ Intriguingly, like the higher myeloid output of FL HSCs (noted above), this property of HSCs, in mice, changes concomitantly with the decrease in their proliferative activity between 3 and 4 weeks after birth. ${ }^{65}$

Responsiveness to growth factors. Steel factor (SF) is a transmembrane growth factor that is encoded by the $S l$ locus. SF binds to Kit (CD117), a type III receptor tyrosine kinase encoded by a gene in the $W$ locus. Even before the products encoded by the $W$ and $S l$ loci were known to represent a receptor-ligand pair mediating HSC responses, studies of the defects caused by mutations at both loci had pointed to their complementary involvement in HSC regulation. For example, both fetal and adult hematopoietic tissues from mice carrying mutations within the kinase domain of Kit show reduced colony formation by CFU-S. ${ }^{79}$ Mice with a $W^{41} / W^{41}$ genotype are of particular interest because they are viable and fertile (in contrast to those with more severe $W$ mutations), ${ }^{80}$ but still have significantly reduced HSC functionality as assessed in limiting dilution transplant assays (10- to 20 -fold). As a result, sublethally irradiated adult $W^{41} / W^{41}$ mice can be used as hosts to enable the detection of transplanted (wild-type) HSCs with the same sensitivity as lethally irradiated wild-type hosts given a minimal radioprotective transplant. ${ }^{81}$ In contrast, $\mathrm{Sl}$-mutant mice, which have deletions in the SF genomic sequence, ${ }^{82}$ have a microenvironmental niche defect that prevents the formation of spleen colonies by CFU-S, as well as the regeneration and maintenance of their numbers throughout adult life. ${ }^{79}$

In the mouse, HSCs from all stages of development express the same levels of Kit on the cell surface regardless of their cycling status or position in the cell cycle. ${ }^{68,83-85}$ However, several lines of evidence point to differences in the requirements and responsiveness of fetal and adult HSCs to $\mathrm{SF}$ stimulation. $\mathrm{Sl} / \mathrm{Sl}$ mice do not express any form of SF and die around E15-16 due to the dependence of fetal as well as adult erythropoiesis on this growth factor. However, their CFU-S and $\mathrm{Thy}^{\mathrm{lo}} \mathrm{Lin}^{-} \mathrm{Sca}-1^{+}$hematopoietic stem and progenitor cells increase at the same rate as their wild-type counterparts, three- to fivefold between E13-15, thus demonstrating that fetal HSC expansion can occur 'normally' in the absence of SF. ${ }^{83}$ In vitro, fetal mouse HSCs can be shown to be SF responsive, but stimulation of their self-renewal is sixfold more sensitive to SF than adult HSCs. ${ }^{84,86-88}$

Fetal B-cell progenitors in the mouse also differ from their adult counterparts with respect to their responsiveness to growth factors. In this case, they are able to give rise to mature progeny without interleukin-7 and thymic stromal-derived lymphopoietin, factors that are necessary for maturation of adult BM-derived progenitors. ${ }^{89}$ Interestingly, the timing of this developmental transition (that is, from interleukin-7 and thymic stromal-derived lymphopoietin independence to dependence) occurs 1-2 weeks after birth, a time point strikingly similar to postnatal changes affecting several other HSC properties. ${ }^{65,68}$

\section{Regulation of developmental changes in HSC properties}

The evidence that most, if not all, adult HSCs and the blood cells they subsequently generate, are derived from fetal HSCs implies that HSCs undergo changes that influence the molecular programs active within them and their differentiating progeny. This possibility is further supported by the recent discovery of specific pathways regulating the different behavior of fetal and adult HSCs, and the associated differences in the transcriptome of prospectively isolated fetal and adult HSCs. ${ }^{75,90,91}$

The concept that some genes may only be required for HSC functioning at certain developmental stages was first demonstrated for Bmil, a member of the polycomb-repressive complex. When this gene is deleted, a normal HSC population is generated in the FL; however, BM failure secondary to HSC depletion occurs 1-2 months after birth, ${ }^{92}$ a time point which directly follows the fetal-to-adult transition in several HSC properties. ${ }^{65,89}$ Similarly, $\mathrm{Gf}^{-/-}$mice develop normally, but when their BM cells are transplanted they have a reduced ability to repopulate irradiated recipients suggesting their adult HSCs are impaired. $.^{93} \mathrm{Tel} / \mathrm{Etv} 6$ has also been shown to be an essential and selective regulator of adult HSC survival. ${ }^{94}$ More recently, the transcription factor $\mathrm{C} / \mathrm{EBPa}$ was shown to be required for acquisition of quiescence of mouse adult HSCs but not by fetal HSCs, which are naturally cycling. ${ }^{72}$

Conversely, several gene products have recently been demonstrated to be important for fetal but not adult HSCs. The first of these identified was Sox17, which is expressed at a higher level in fetal compared with adult HSCs, using both direct measurements of gene expression and an analysis of HSCs isolated from a Sox 17 knock-in reporter mouse. ${ }^{95}$ Inducible deletion of the Sox17 gene was then used to 
demonstrate an essential role for Sox17 in maintaining HSCs in fetal/neonatal mice. Importantly, Sox17 deletion in adult mice had no effect on HSC numbers or functionality; ${ }^{95}$ however, forced expression of Sox17 in adult BM was found to enhance the HSC-derived output of myeloid cells (a fetal HSC property). ${ }^{96}$

Another central question regarding developmental changes in HSC properties is whether the timing, onset and maintenance of such changes are governed by extrinsic factors (that is, hormones, growth factors or paracrine 'niche' signals) or intrinsic factors (that is, cell-intrinsic timers and epigenetics). While it is known that FL stromal cells express factors such as insulin-like growth factor $2^{97}$ and angiopoietin-like factors ${ }^{98}$ that would be anticipated to supply a unique set of signals to HSCs in the FL as compared with the adult BM microenvironment, there is also evidence that HSC developmental states and transitions are intrinsically regulated-likely a complex interplay of both is operative.

Direct evidence for a cell-intrinsic mechanism underlying the developmentally coordinated changes in properties of fetal and adult HSCs has been obtained from several recent studies. Our own work has implicated the Lin28b-let-7-Hmga2 pathway. ${ }^{91}$ In a comparison of E14.5 FL and adult BM HSCs purified from mice, we found that Lin28b is expressed at higher levels in the fetal HSCs and lentivirus-mediated overexpression of Lin28b in adult HSCs led to heightened Hmga2 levels through inhibition of the let-7 family of messenger RNAs(miRNAs). Moreover, lentivirus-mediated overexpression of either Lin28b (or its homologue Lin28) in adult HSCs enhanced the self-renewal activity of the HSCs to mimic that typical of FL HSCs when transplanted into irradiated hosts. In addition, this result was phenocopied by overexpression of Hmga2 in adult HSCs. Conversely, fetal HSCs from Hmga2-null mice display an adult-like, reduced self-renewal activity in the same type of transplantation experiment. Together, these findings demonstrate that Lin $28 \mathrm{~b}$ is a master determinant of the high self-renewal of fetal HSCs and acts by permitting a high-level of Hmga 2 expression in these cells.

Similarly to HSCs, Lin28b is expressed at higher levels in B-cell precursors in the mouse E14.5 FL as compared with similar subsets in the adult BM. ${ }^{60}$ Moreover, ectopic overexpression of Lin28 in adult BM hematopoietic stem and progenitor cells can activate many of the fetal lymphoid phenotypes summarized above. ${ }^{60}$ Strikingly, Lin28-mediated fetal-like reprogramming of adult BM cells also induce a fetallike interleukin-7 and thymic stromal-derived lymphopoietin independence upon B progenitors. ${ }^{60}$ However, Lin28-mediated activation of several of these fetal lymphoid phenotypes is not mediated by Hmga2 derepression, as direct overexpression of this gene cannot activate them. ${ }^{91}$

Let-7 miRNAs also regulate developmental differences in megakaryopoiesis ${ }^{99}$ and control human fetal hemoglobin expression. ${ }^{100}$ This latter let-7-mediated effect was also shown to be a consequence of LIN28B expression, which leads to reduced levels of BCL11A, a known repressor of $\gamma$-globin expression. Together, these findings strongly support a role for the Lin28b-let-7 axis as a 'master regulator' of the fetal HSC state (Figure 1). Intriguingly, while the Lin28b-let-7 pairing seems to be a common feature of many fetal-specific properties of HSCs, the downstream target of this pairing appears to be property-dependent. For example, in mice, Hmga2 is the downstream mediator of developmental differences in HSC self-renewal, with BCL11A being identified as downstream of LIN28B-induced $\mathrm{HbF}$ activation in human erythroid cells.

Hmga $2,{ }^{91} \operatorname{Lin}_{28 b^{60}}$ and let-7 miRNAs ${ }^{60}$ change their levels gradually between fetal and adult life. This suggests that these genes may be components of a developmental clock, in which the timing is determined by accumulation and/or titration of
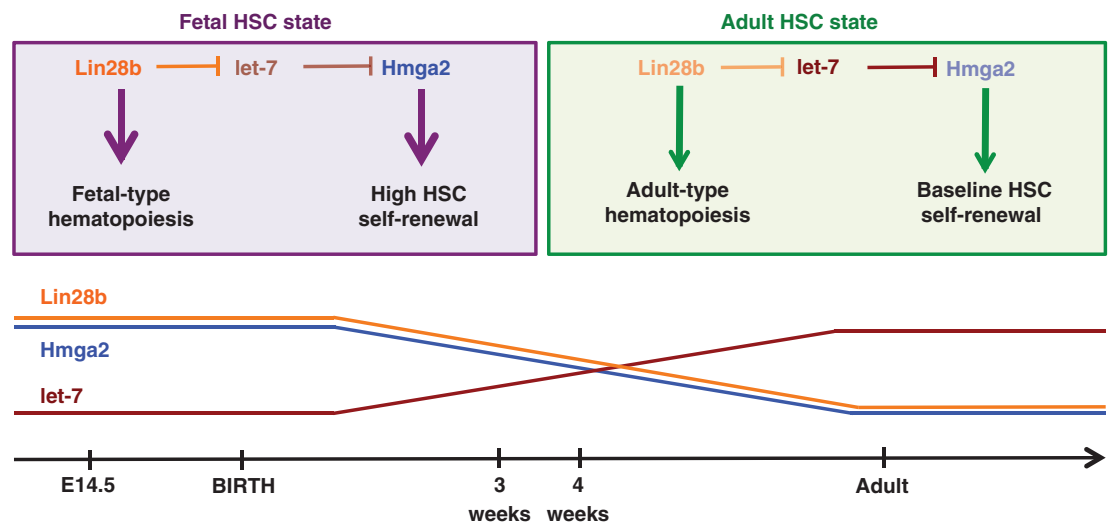

Figure $1 \mathrm{Lin} 28 \mathrm{~b}$ is a master regulator of fetal hematopoietic stem cell (HSC) identity. The higher level of Lin28b expression in fetal (as compared with adult) HSCs leads to a correspondingly lower level of let-7 messenger RNAs (miRNAs) and thus permits a higher expression of Hmga2. This elevated level of Hmga2 is responsible for the enhanced self-renewal activity of fetal as compared with adult HSCs in the mouse. ${ }^{91}$ Lin28b also regulates other differences seen between fetal and adult hematopoiesis; for example, the activation of fetal-type lymphopoiesis ${ }^{60}$ and the expression (in human erythroid cells) of fetal hemoglobin. ${ }^{100}$ These properties are not a consequence of Lin28b-mediated derepression of Hmga2 expression. ${ }^{91,100}$ This figure is modified with permission from a previously published version. ${ }^{91}$ 
these molecules. The Lin28-let-7 pairing has been previously implicated in the regulation of such a developmental transition in Caenorhabditis elegans. This larval-to-adult transition, which involves a switch from cycling to quiescence of a stem-like population known as seam cells, is regulated by the downregulation of Lin28, which in turn triggers an upregulation of let-7. ${ }^{101}$ In let-7-mutant animals, the seam cells do not exit the cell cycle but instead reiterate a larval fate. ${ }^{101}$ Thus, the timing mechanism of this transition is thought to involve the accumulation of let-7 miRNAs. The findings that let-7 levels increase in HSCs between fetal and adult life ${ }^{60}$ bear a striking resemblance to this larval-to-adult transition of C. elegans. Thus, the developmental downregulation of Lin $28 \mathrm{~b}$, which regulates the differences in the self-renewal activities and lymphoid differentiation potential of fetal compared with adult HSCs, may also be responsible for the timing of this transition that occurs between 3 and 4 weeks of age. This also raises the possibility that such cell-intrinsic development timing mechanisms represent highly evolutionarily conserved processes.

As mentioned, developmental transitions of hematopoietic cells not only occur in HSCs, but also in megakaryocyte progenitors, ${ }^{49,50}$ myeloid progenitors, ${ }^{9,10}$ CFU-E, ${ }^{43}$ B-cell progenitors ${ }^{52,89}$ and T-cells. ${ }^{57}$ Furthermore, as the differential expression pattern of Lin28b, let-7 miRNAs and Hmga2 between fetal and adult HSCs is also apparent in populations composed principally of hematopoietic progenitors (that is, $\mathrm{Lin}^{-} \mathrm{Sca}{ }^{+} \mathrm{Kit}^{+}$cells), ${ }^{91}$ this suggests that developmental programs active within HSCs may remain active within more differentiated hematopoietic subsets. This is supported by the recent evidence that let-7 miRNAs also regulate developmental differences in B-cells, T-cells ${ }^{60}$ and megakaryocytes. ${ }^{99}$

\section{Clinical implications}

Pathogenesis of pediatric malignancies. Approximately $2 \%$ of all cancer cases in western countries occur in children before they reach 15 years of age. ${ }^{102}$ These include, in descending order of prevalence, leukemia, lymphoma, CNS tumors, neuroblastomas, soft-tissue sarcomas, nephroblastomas (Wilms' tumor), bone tumors, retinoblastomas, hepatoblastomas and germ cell tumors. ${ }^{102}$ In contrast to adult leukemias, which are most frequently myeloid diseases, the majority of those occurring in children are acute lymphoblastic leukemias. ${ }^{103}$ Interestingly, the incidence of acute lymphoblastic leukemias does not increase gradually throughout childhood, but rather shows a peak at approximately 5 years of age. ${ }^{102}$ It may, therefore, be speculated that the microenvironment and/or leukemia-initiating cells undergo a transition in their susceptibility to oncogenic transformation during early childhood.

This concept is strengthened by the observation of pediatric-exclusive mutations and susceptibility syndromes, and examples of spontaneous age-associated tumor regression in children. The TEL-AML1 fusion oncogene is the most frequent mutation found in pediatric acute lymphoblastic leukemias, present in $\sim 25 \%$ of all cases, ${ }^{104}$ but is rarely, if ever, found in adult acute lymphoblastic leukemias. ${ }^{105}$ While the reasons for this remain unknown, a possible explanation could be the absence or presence of different protective or cooperating factors in the hematopoietic cells of children but not adults. This explanation could also apply to the window of early childhood in which patients with Noonan syndrome appear to be at an increased risk of developing leukemia, a risk that subsequently decreases to a baseline level despite the persistence of the responsible inherited genetic lesions. ${ }^{106}$ Additional evidence of age-specific cooperating oncogenic factors can be inferred from the observations of occasional pediatric leukemias that resolve spontaneously. One example, although rare, are cases of juvenile myelomonocytic leukemia that may regress, even in the absence of treatment. ${ }^{107}$ Similarly, a megakaryoblastic leukemia that occurs exclusively in children with Down syndrome, known as the transient myeloproliferative disorder, can also spontaneously resolve within the first 3 months of life. ${ }^{108}$ Notably, even some pediatric solid tumors undergo a spontaneous regression. ${ }^{102}$

Lin28b and Hmga2 are oncogenes, ${ }^{109,110}$ whereas let-7 miRNAs are tumor suppressors. ${ }^{111}$ Thus, the expression pattern of these genes in fetal and neonatal hematopoietic cells would be anticipated to create a 'primed' background for the generation of leukemia. Furthermore, these genes are cell intrinsically programmed to switch their expression pattern during the transition to adulthood, which might serve as a mechanism responsible for the occasionally observed spontaneous regression of certain fetal/neonatal onset leukemic disorders. In these cases, the 'developmental hits,' which are cooperating with acquired or genetic lesions, would be predicted to be downregulated during early life, thus leading to a collapse of the molecular program driving the progression of these diseases. The recently elucidated role of the HMGA2IGF2BP2 axis in the pathogenesis of NRAS-mutant embryonic rhabdomyosarcoma ${ }^{112}$ lends strong support for this idea.

HSC transplantation. HSC transplantation is a well-established technique that has been used to treat over 30 different types of familial and acquired hematologic diseases. ${ }^{113}$ A major barrier to patient access to allogeneic HSC transplantation is the requirement to have a human leukocyte antigen-matched donor. Currently, $\sim 30 \%$ of patients requiring allogeneic HSC transplantation are not candidates for this life-saving procedure due to lack of a suitable donor. ${ }^{113}$ Three general strategies have been proposed to improve the supply of HSC transplantation sources in order to permit more patients access to this treatment. The first of these, sometimes referred to as the 'holy grail' of translational HSC research, is the ex vivo expansion of HSCs. As this occurs readily in vivo (that is, following HSC transplantation or during growth and development), it should theoretically be possible to replicate these conditions in vitro, and thereby enable the generation of a large supply of HSCs even using autologous sources when these may be limiting. However, in spite of substantial efforts to identify such conditions, the most recent protocols offer only modest, if any, net increases in HSC numbers. ${ }^{114}$ Another 
approach has been to direct the differentiation of embryonic stem cells or induced pluripotent stem cells to a hematopoietic fate. This has also been met with limited success to date and has netted only convincing evidence for the generation of hematopoietic progenitors. ${ }^{115}$ The third of such strategies has been the use of alternate sources of HSCs, most notably CB. $\mathrm{CB}$ transplants are now routinely used in the pediatric setting; but their utility in adults is more problematic due to the limiting numbers of repopulating cells in individual $\mathrm{CB}$ collections. ${ }^{116}$

An additional strategy is to manipulate HSCs ex vivo in a manner that will enhance their rate of expansion in transplant recipients. This could theoretically increase the effective cell dose, and in turn broaden the utility of $\mathrm{CB}$ and/or ex vivoexpanded HSCs. Evidence of such an effect is found in the dominant clones containing HMGA2 insertional mutations observed in several clinical gene therapy trials. Using new sequencing technologies, the clonal dynamics of HSC and progenitor cells within patients undergoing gene therapy for hematologic conditions can be studied. In a recent report of eight patients who were being monitored following a transplantation of lentivirus-corrected autologous BM cells for treatment of their X-linked severe combined immunodeficiency, two patients were found to harbor clones where the viral cassette had inserted within the large third intron of the HMGA2 gene. In both of these cases, the HMGA2 insertional mutant clone demonstrated a dominant behaviour, with one clone representing $6 \%$ of all transduced cells. ${ }^{117}$ In both of these cases, the mutation generated a truncated transcript lacking the let-7 miRNA binding sites, thus leading to derepression (that is overexpression) of HMGA2. A similar mutation and case of clonal dominance were recently reported in a patient undergoing gene therapy treatment for $\beta$ thalassemia. Interestingly, in this case, the clonal dominance was responsible for the therapeutic effect, as it permitted the pool of corrected HSCs to reach a therapeutic threshold. ${ }^{118}$ This finding suggests that deliberate overexpression of HMGA2 in parallel with the transgene of interest might similarly enhance the efficacy of such a therapy and be particularly useful in cases like $\beta$-thalassemia where a large portion of HSCs must be corrected in order to achieve a benefit.

\section{Conclusions and future directions}

As summarized in this review, HSCs in mice and humans undergo a multitude of developmental changes that alter the properties of themselves and the more committed progeny they produce. Molecular regulators of some of these processes have recently been identified, most notably the Lin $28 b-l e t-7$ axis, which regulates multiple developmentally determined changes. Importantly, this pathway and its downstream targets, including Hmga2 and Igf2bp2, are differentially expressed across development and/or responsible for developmental differences in stem cell properties of other tissue-specific stem cells across different species. ${ }^{101,119-122}$ Thus, we predict that this pathway will be found to be responsible for modulating many core properties of diverse stem cell types that must change to support organismal growth and its eventual arrest.

Future studies focused on the relevance of this pathway to human HSC biology are also anticipated. Observations of dominant HMGA2-activated clones in patients undergoing gene therapy treatments ${ }^{117}$ has provided convincing evidence that the let-7-HMGA2 pairing is active in human HSCs, and that HMGA2 may activate a fetal-like self-renewal potential in these cells. It is also established that Lin $28 \mathrm{~b}$ is expressed at significantly higher levels in human FL and CB as compared with adult hematopoietic tissues (BM, thymus and lymph nodes) ${ }^{60}$ It will thus be particularly interesting to discover whether LIN28 expression can influence the susceptibility of naïve human HSCs to transformation and whether fetal-specific pathways are aberrantly activated in adult malignancies in which LIN28, LIN28B or HMGA2 mutations are present.

\section{ACKNOWLEDGEMENTS}

We thank Philip Beer for helpful comments. This review was prepared with the support from grants funded by the National Cancer Institute of Canada (NCIC, with funds from the Terry Fox Run), the Canadian Institutes of Health Research (CIHR), the Canadian Cancer Society (grant 700374) and the Terry Fox Foundation. MRC received a Vanier Canada Graduate Scholarship from CIHR, a Michael Smith

Foundation for Health Research (MSFHR) Graduate Studentship and an $\mathrm{MD} / \mathrm{PhD}$ Graduate Training Award from CIHR.

1 Szilvassy SJ, Ragland PL, Miller CL, Eaves CJ. The marrow homing efficiency of murine hematopoietic stem cells remains constant during ontogeny. Exp Hematol 2003; 31: 331-338.

2 Doulatov S, Notta F, Laurenti E, Dick JE. Hematopoiesis: a human perspective. Cell Stem Cell 2012; 10: 120-136.

3 Lessard J, Faubert A, Sauvageau G. Genetic programs regulating HSC specification, maintenance and expansion. Oncogene 2004; 23: 7199-7209.

4 Purton LE, Scadden DT. Limiting factors in murine hematopoietic stem cell assays. Cell Stem Cell 2007; 1: 263-270.

5 Dykstra B, Kent D, Bowie M, McCaffrey L, Hamilton M, Lyons $\mathrm{K}$ et al. Long-term propagation of distinct hematopoietic differentiation programs in vivo. Cell Stem Cell 2007; 1: 218-229.

6 Kent DG, Copley MR, Benz C, Wohrer S, Dykstra BJ, Ma E et al. Prospective isolation and molecular characterization of hematopoietic stem cells with durable self-renewal potential. Blood 2009; 113: 6342-6350.

7 Benz C, Copley M, Kent D, Wohrer S, Cores A, Aghaeepour N et al. Hematopoietic stem cell subtypes expand differentially during development and display distinct lymphopoietic programs. Cell Stem Cell 2012; 10: 273-283.

8 Copley MR, Beer PA, Eaves CJ. Hematopoietic stem cell heterogeneity takes center stage. Cell Stem Cell 2012; 10: 690-697.

9 Becker AJ, McCulloch EA, Siminovitch L, Till JE. The effect of differing demands for blood cell production on DNA synthesis by hemopoietic colony-forming cells of mice. Blood 1965; 26: 296-308.

10 Schofield RA. Comparative study of repopulating potential of grafts from various haemopoietic sources: CFU repopulation. Cell Tissue Kinet 1970; 3: $119-130$

11 Micklem HS, Ford CE, Evans EP, Ogden DA, Papworth DS. Competitive in vivo proliferation of foetal and adult haematopoietic cells in lethally irradiated mice. J Cell Physiol 1972; 79: 293-298.

12 Signer RA, Morrison SJ. Mechanisms that regulate stem cell aging and life span. Cell Stem Cell 2013; 12: 152-165. 
13 Till JE, McCulloch EA. A direct measurement of the radiation sensitivity of normal mouse bone marrow cells. Radiat Res 1961; 14: 213-222.

14 Siminovitch L, McCulloch EA, Till JE. The distribution of colony-forming cells among spleen colonies. J Cell Physiol 1963; 62: 327-336.

15 Becker AJ, McCulloch EA, Till JE. Cytological demonstration of the clonal nature of spleen colonies derived from transplanted mouse marrow cells. Nature 1963; 197: 452-454.

16 Ploemacher RE, Brons RH. Separation of CFU-S from primitive cells responsible for reconstitution of the bone marrow hemopoietic stem cell compartment following irradiation: evidence for a pre-CFU-S cell. Exp Hematol 1989; 17: 263-266.

17 Jones RJ, Collector MI, Barber JP, Vala MS, Fackler MJ, May WS et al. Characterization of mouse lymphohematopoietic stem cells lacking spleen colony-forming activity. Blood 1996; 88: 487-491.

18 Holyoake TL, Nicolini FE, Eaves CJ. Functional differences between transplantable human hematopoietic stem cells from fetal liver, cord blood, and adult marrow. Exp Hematol 1999; 27: 1418-1427.

19 Nicolini FE, Holyoake TL, Cashman JD, Chu PP, Lambie K, Eaves CJ. Unique differentiation programs of human fetal liver stem cells shown both in vitro and in vivo in NOD/SCID mice. Blood 1999; 94: 2686-2695.

20 Cumano A, Godin I. Ontogeny of the hematopoietic system. Annu Rev Immunol 2007; 25: 745-785.

21 Palis J, Yoder MC. Yolk-sac hematopoiesis: the first blood cells of mouse and man. Exp Hematol 2001; 29: 927-936.

22 Wong PM, Chung SW, Eaves CJ, Chui DH. Ontogeny of the mouse hemopoietic system. Prog Clin Biol Res 1985; 193: 17-28.

23 Charbord P, Tavian M, Coulombel L, Luton D, San Clemente H, Humeau L et al. [Early ontogeny of the human hematopoietic system]. C R Seances Soc Biol Fil 1995; 189: 601-609.

24 Medvinsky AL, Samoylina NL, Muller AM, Dzierzak EA. An early pre-liver intraembryonic source of CFU-S in the developing mouse. Nature 1993 364: 64-67.

25 Muller AM, Medvinsky A, Strouboulis J, Grosveld F, Dzierzak E. Development of hematopoietic stem cell activity in the mouse embryo. Immunity 1994; 1: 291-301.

26 Medvinsky A, Dzierzak E. Definitive hematopoiesis is autonomously initiated by the AGM region. Cell 1996; 86: 897-906.

27 de Bruijn MF, Speck NA, Peeters MC, Dzierzak E. Definitive hematopoietic stem cells first develop within the major arterial regions of the mouse embryo. EMBO J 2000; 19: 2465-2474.

28 Ivanovs A, Rybtsov S, Welch L, Anderson RA, Turner ML, Medvinsky A. Highly potent human hematopoietic stem cells first emerge in the intraembryonic aorta-gonad-mesonephros region. J Exp Med 2011; 208: 2417-2427.

29 Gekas C, Dieterlen-Lievre F, Orkin SH, Mikkola HK. The placenta is a niche for hematopoietic stem cells. Dev Cell 2005; 8: 365-375.

30 Rhodes KE, Gekas C, Wang Y, Lux CT, Francis CS, Chan DN et al. The emergence of hematopoietic stem cells is initiated in the placental vasculature in the absence of circulation. Cell Stem Cell 2008; 2: 252-263.

31 Van Handel B, Prashad SL, Hassanzadeh-Kiabi N, Huang A, Magnusson M, Atanassova $\mathrm{B}$ et al. The first trimester human placenta is a site for terminal maturation of primitive erythroid cells. Blood 2010; 116: 3321-3330.

32 Kumaravelu P, Hook L, Morrison AM, Ure J, Zhao S, Zuyev S et al. Quantitative developmental anatomy of definitive haematopoietic stem cells/long-term repopulating units (HSC/RUs): role of the aorta-gonadmesonephros (AGM) region and the yolk sac in colonisation of the mouse embryonic liver. Development 2002; 129: 4891-4899.

33 Yoder MC, Hiatt K, Mukherjee P. In vivo repopulating hematopoietic stem cells are present in the murine yolk sac at day 9.0 postcoitus. Proc Natl Acad Sci USA 1997; 94: 6776-6780.

34 Houssaint E. Differentiation of the mouse hepatic primordium. II. Extrinsic origin of the haemopoietic cell line. Cell Differ 1981; 10: 243-252.

35 Johnson GR, Moore MA. Role of stem cell migration in initiation of mouse foetal liver haemopoiesis. Nature 1975; 258: 726-728.

36 Fleischman RA, Custer RP, Mintz B. Totipotent hematopoietic stem cells: normal self-renewal and differentiation after transplantation between mouse fetuses. Cell 1982; 30: 351-359.

37 Yoder MC. Generation of HSCs in the embryo and assays to detect them. Oncogene 2004: 23: 7161-7163.

38 Mikkola HK, Orkin SH. The journey of developing hematopoietic stem cells. Development 2006; 133: 3733-3744.
39 Robb L, Lyons I, Li R, Hartley L, Kontgen F, Harvey RP et al. Absence of yolk sac hematopoiesis from mice with a targeted disruption of the $\mathrm{scl}$ gene. Proc Natl Acad Sci USA 1995; 92: 7075-7079.

40 Shivdasani RA, Mayer EL, Orkin SH. Absence of blood formation in mice lacking the T-cell leukaemia oncoprotein tal-1/SCL. Nature 1995; 373: 432-434.

41 Samokhvalov IM, Samokhvalova NI, Nishikawa S. Cell tracing shows the contribution of the yolk sac to adult haematopoiesis. Nature 2007; 446: 1056-1061.

42 McGrath K, Palis J. Ontogeny of erythropoiesis in the mammalian embryo. Curr Top Dev Biol 2008; 82: 1-22.

43 Rich IN, Kubanek B. Erythroid colony formation (Cfue) in fetal liver and adult bone-marrow and spleen from mouse. Blut 1976; 33: 171-180.

44 Rich IN, Kubanek B. The ontogeny of erythropoiesis in the mouse detected by the erythroid colony-forming technique.2. Transition in erythropoietin sensitivity during development. J Embryol Exp Morph 1980; 58: 143-155.

45 DeAlarcon PA, Graeve JLA. Analysis of megakaryocyte ploidy in fetal bone marrow biopsies using a new adaptation of the feulgen technique to measure DNA content and estimate megakaryocyte ploidy from biopsy specimens. Pediatr Res 1996; 39: 166-170.

46 Graeve JLA, Dealarcon PA. Megakaryocytopoiesis in the human-fetus. Arch Dis Child 1989; 64: 481-484.

$47 \mathrm{Ma}$ DC, Sun YH, Chang KZ, Zuo W. Developmental change of megakaryocyte maturation and DNA ploidy in human fetus. Eur J Haematol 1996; 57: 121-127.

48 Liu ZJ, Italiano J, Ferrer-Marin F, Gutti R, Bailey M, Poterjoy B et al. Developmental differences in megakaryocytopoiesis are associated with up-regulated TPO signaling through mTOR and elevated GATA-1 levels in neonatal megakaryocytes. Blood 2011; 117: 4106-4117.

49 Murray NA, Watts TL, Roberts IAG. Endogenous thrombopoietin levels and effect of recombinant human thrombopoietin on megakaryocyte precursors in term and preterm babies. Pediatr Res 1998; 43: 148-151.

50 Nishihira H, Toyoda Y, Miyazaki H, Kigasawa H, Ohsaki E. Growth of macroscopic human megakaryocyte colonies from cord blood in culture with recombinant human thrombopoietin (c-mpl ligand) and the effects of gestational age on frequency of colonies. Br J Haematol 1996; 92 : 23-28.

51 Klimchenko O, Di Stefano A, Geoerger B, Hamidi S, Opolon P, Robert T et al. Monocytic cells derived from human embryonic stem cells and fetal liver share common differentiation pathways and homeostatic functions. Blood 2011; 117: 3065-3075.

52 Hayakawa K, Hardy RR, Herzenberg LA, Herzenberg LA. Progenitors for Ly-1 B-Cells are distinct from progenitors for other B-cells. J Exp Med 1985; 161: 1554-1568.

53 Carvalho TL, Mota-Santos T, Cumano A, Demengeot J, Vieira P. Arrested B lymphopoiesis and persistence of activated $B$ cells in adult interleukin 7(-/-) mice. J Exp Med 2001; 194: 1141-1150.

54 Carey JB, Moffatt-Blue CS, Watson LC, Gavin AL, Feeney AJ. Repertoirebased selection into the marginal zone compartment during $B$ cel development. J Exp Med 2008; 205: 2043-2052.

55 Yoshimoto $M$, Montecino-Rodriguez E, Ferkowicz MJ, Porayette $P$ Shelley WC, Conway SJ et al. Embryonic day 9 yolk sac and intraembryonic hemogenic endothelium independently generate a B-1 and marginal zone progenitor lacking B-2 potential. Proc Natl Acad Sci USA 2011; 108: 1468-1473.

56 Havran WL, Allison JP. Developmentally ordered appearance of thymocytes expressing different T-cell antigen receptors. Nature 1988; 335: 443-445.

57 Ikuta K, Kina T, MacNeil I, Uchida N, Peault B, Chien YH et al. A developmental switch in thymic lymphocyte maturation potential occurs at the level of hematopoietic stem cells. Cell 1990; 62 863-874.

58 Benlagha K, Kyin T, Beavis A, Teyton L, Bendelac A. A thymic precursor to the NK T cell lineage. Science 2002; 296: 553-555.

59 Gapin L, Matsuda JL, Surh CD, Kronenberg M. NKT cells derive from double-positive thymocytes that are positively selected by CD1d. Nat Immunol 2001; 2: 971-978.

60 Yuan J, Nguyen CK, Liu X, Kanellopoulou C, Muljo SA. Lin28b reprograms adult bone marrow hematopoietic progenitors to mediate fetal-like lymphopoiesis. Science 2012; 335: 1195-1200.

61 Challen GA, Boles NC, Chambers SM, Goodell MA. Distinct hematopoietic stem cell subtypes are differentially regulated by TGF-beta1. Cell Stem Cell 2010; 6: 265-278. 
62 Morita Y, Ema H, Nakauchi $\mathrm{H}$. Heterogeneity and hierarchy within the most primitive hematopoietic stem cell compartment. J Exp Med 2010; 207: 1173-1182.

63 Heyworth C, Pearson S, May G, Enver T. Transcription factor-mediated lineage switching reveals plasticity in primary committed progenitor cells. EMBO J 2002; 21: 3770-3781.

64 Sieburg HB, Cho RH, Dykstra B, Uchida N, Eaves CJ, Muller-Sieburg CE. The hematopoietic stem compartment consists of a limited number of discrete stem cell subsets. Blood 2006; 107: 2311-2316.

65 Bowie MB, Kent DG, Dykstra B, McKnight KD, McCaffrey L, Hoodless PA et al. Identification of a new intrinsically timed developmental checkpoint that reprograms key hematopoietic stem cell properties. Proc Natl Acad Sci USA 2007; 104: 5878-5882.

66 Fleming WH, Alpern EJ, Uchida N, Ikuta K, Spangrude GJ, Weissman IL. Functional heterogeneity is associated with the cell cycle status of murine hematopoietic stem cells. J Cell Biol 1993; 122: 897-902.

67 Morrison SJ, Hemmati HD, Wandycz AM, Weissman IL. The purification and characterization of fetal liver hematopoietic stem cells. Proc Natl Acad Sci USA 1995; 92: 10302-10306.

68 Bowie MB, McKnight KD, Kent DG, McCaffrey L, Hoodless PA, Eaves CJ. Hematopoietic stem cells proliferate until after birth and show a reversible phase-specific engraftment defect. J Clin Invest 2006; 116: 2808-2816.

69 Rufer N, Brummendorf TH, Kolvraa S, Bischoff C, Christensen K, Wadsworth $\mathrm{L}$ et al. Telomere fluorescence measurements in granulocytes and $\mathrm{T}$ lymphocyte subsets point to a high turnover of hematopoietic stem cells and memory T cells in early childhood. J Exp Med 1999; 190: 157-167.

70 Sidorov I, Kimura M, Yashin A, Aviv A. Leukocyte telomere dynamics and human hematopoietic stem cell kinetics during somatic growth. Exp Hematol 2009; 37: 514-524.

71 Baerlocher GM, Rice K, Vulto I, Lansdorp PM. Longitudinal data on telomere length in leukocytes from newborn baboons support a marked drop in stem cell turnover around 1 year of age. Aging cell 2007; 6: 121-123.

72 Ye M, Zhang H, Amabile G, Yang H, Staber PB, Zhang P et al. C/EBPa controls acquisition and maintenance of adult haematopoietic stem cell quiescence. Nat Cell Biol 2013; 15: 385-394.

73 Trumpp A, Essers M, Wilson A. Awakening dormant haematopoietic stem cells. Nat Rev Immunol 2010; 10: 201-209.

74 Venezia TA, Merchant AA, Ramos CA, Whitehouse NL, Young AS, Shaw $\mathrm{CA}$ et al. Molecular signatures of proliferation and quiescence in hematopoietic stem cells. PLoS Biol 2004; 2: 1640-1651.

75 McKinney-Freeman S, Cahan P, Li H, Lacadie SA, Huang HT, Curran M et al. The transcriptional landscape of hematopoietic stem cell ontogeny. Cell Stem Cell 2012; 11: 701-714.

76 Rebel VI, Miller CL, Thornbury GR, Dragowska WH, Eaves CJ, Lansdorp $\mathrm{PM}$. A comparison of long-term repopulating hematopoietic stem cells in fetal liver and adult bone marrow from the mouse. Exp Hematol 1996; 24: 638-648.

77 Rebel VI, Miller CL, Eaves CJ, Lansdorp PM. The repopulation potential of fetal liver hematopoietic stem cells in mice exceeds that of their liver adult bone marrow counterparts. Blood 1996; 87: 3500-3507.

78 Pawliuk R, Eaves C, Humphries RK. Evidence of both ontogeny and transplant dose-regulated expansion of hematopoietic stem cells in vivo. Blood 1996; 88: 2852-2858.

79 McCulloch EA, Siminovitch L, Till JE. Spleen-colony formation in anemic mice of genotype Ww. Science 1964; 144: 844-846.

80 Geissler EN, Mcfarland EC, Russell ES. Analysis of pleiotropism at the dominant white-spotting (W) locus of the house mouse - a description of 10 new W-alleles. Genetics 1981; 97: 337-361.

81 Miller CL, Rebel VI, Lemieux ME, Helgason CD, Lansdorp PM, Eaves CJ. Studies of $\mathrm{W}$ mutant mice provide evidence for alternate mechanisms capable of activating hematopoietic stem cells. Exp Hematol 1996; 24: 185-194.

82 Huang E, Nocka K, Beier DR, Chu TY, Buck J, Lahm HW et al. The hematopoietic growth factor-KI is encoded by the Si-locus and is the ligand of the C-Kit receptor, the gene-product of the W-locus. Cell 1990; 63: 225-233.

83 Ikuta K, Weissman IL. Evidence that hematopoietic stem cells express mouse c-kit but do not depend on steel factor for their generation. Proc Natl Acad Sci USA 1992; 89: 1502-1506.

84 Bowie MB, Kent DG, Copley MR, Eaves CJ. Steel factor responsiveness regulates the high self-renewal phenotype of fetal hematopoietic stem cells. Blood 2007; 109: 5043-5048.
85 Ashman LK. The biology of stem cell factor and its receptor C-kit. Int J Biochem Cell B. 1999; 31: 1037-1051.

86 Audet J, Miller CL, Eaves CJ, Piret JM. Common and distinct features of cytokine effects on hematopoietic stem and progenitor cells revealed by dose-response surface analysis. Biotechnol Bioeng 2002; 80: 393-404.

87 Zandstra PW, Conneally E, Petzer AL, Piret JM, Eaves CJ. Cytokine manipulation of primitive human hematopoietic cell self-renewal. Proc Natl Acad Sci USA 1997; 94: 4698-4703.

88 Uchida N, Dykstra B, Lyons KJ, Leung FY, Eaves CJ. Different in vivo repopulating activities of purified hematopoietic stem cells before and after being stimulated to divide in vitro with the same kinetics. Exp Hematol 2003; 31: 1338-1347.

89 Kikuchi K, Kondo M. Developmental switch of mouse hematopoietic stem cells from fetal to adult type occurs in bone marrow after birth. Proc Natl Acad Sci USA 2006; 103: 17852-17857.

90 Kiel MJ, Iwashita T, Yilmaz OH, Morrison SJ. Spatial differences in hematopoiesis but not in stem cells indicate a lack of regional patterning in definitive hematopoietic stem cells. Dev Biol 2005; 283: 29-39.

91 Copley MR, Babovic S, Benz C, Knapp DJ, Beer PA, Kent DG et al. The Lin28b-let-7-Hmga2 axis determines the higher self-renewal potential of fetal haematopoietic stem cells. Nat Cell Biol 2013; 15: 916-925.

92 Park IK, Qian D, Kiel M, Becker MW, Pihalja M, Weissman IL et al. Bmi-1 is required for maintenance of adult self-renewing haematopoietic stem cells. Nature 2003; 423: 302-305.

93 Hock H, Hamblen MJ, Rooke HM, Schindler JW, Saleque S, Fujiwara Y et al. Gfi-1 restricts proliferation and preserves functional integrity of haematopoietic stem cells. Nature 2004; 431: 1002-1007.

94 Hock H, Meade E, Medeiros S, Schindler JW, Valk PJ, Fujiwara Y et al. Tel/Etv6 is an essential and selective regulator of adult hematopoietic stem cell survival. Genes Dev 2004; 18: 2336-2341.

95 Kim I, Saunders TL, Morrison SJ. Sox17 dependence distinguishes the transcriptional regulation of fetal from adult hematopoietic stem cells. Cell 2007; 130: 470-483.

$96 \mathrm{He} \mathrm{S}, \mathrm{Kim}$ I, Lim MS, Morrison SJ. Sox17 expression confers self-renewal potential and fetal stem cell characteristics upon adult hematopoietic progenitors. Genes Dev 2011; 25: 1613-1627.

97 Zhang CC, Lodish HF. Insulin-like growth factor 2 expressed in a novel fetal liver cell population is a growth factor for hematopoietic stem cells. Blood 2004; 103: 2513-2521.

98 Zhang CC, Kaba M, Ge G, Xie K, Tong W, Hug C et al. Angiopoietin-like proteins stimulate ex vivo expansion of hematopoietic stem cells. Nat Med 2006; 12: 240-245.

99 Gutti RK, Sallmon H, Liu ZJ, Ferrer-Marin F, Cantor A, Bailey M et al. Developmental differences in the Let-7b/IMP-1/IGF-II axis contribute to the high proliferative rate of neonatal megakaryocyte progenitors. Blood 2010; 116: 674.

100 Lee YT, de Vasconcellos JF, Yuan J, Byrnes C, Noh SJ, Meier ER et al. LIN28B-mediated expression of fetal hemoglobin and production of fetal-like erythrocytes from adult human erythroblasts ex vivo. Blood 2013; 122: 1034-1041.

101 Bussing I, Slack FJ, Grosshans H. let-7 microRNAs in development, stem cells and cancer. Trends Mol Med 2008; 14: 400-409.

102 Scotting PJ, Walker DA, Perilongo G. Childhood solid tumours: a developmental disorder. Nat Rev Cancer. 2005; 5: 481-488.

103 Roberts KG, Mullighan CG. How new advances in genetic analysis are influencing the understanding and treatment of childhood acute leukemia. Curr Opin Pediatr 2011; 23: 34-40.

104 Speck NA, Gilliland DG. Core-binding factors in haematopoiesis and leukaemia. Nat Rev Cancer 2002; 2: 502-513.

105 Schindler JW, Van Buren D, Foudi A, Krejci O, Qin J, Orkin SH et al. TEL-AML1 corrupts hematopoietic stem cells to persist in the bone marrow and initiate leukemia. Cell Stem Cell 2009; 5: 43-53.

106 Romano AA, Allanson JE, Dahlgren J, Gelb BD, Hall B, Pierpont ME et al. Noonan syndrome: clinical features, diagnosis, and management guidelines. Pediatrics 2010; 126: 746-759.

107 Matsuda K, Shimada A, Yoshida N, Ogawa A, Watanabe A, Yajima S et al. Spontaneous improvement of hematologic abnormalities in patients having juvenile myelomonocytic leukemia with specific RAS mutations. Blood 2007; 109: 5477-5480.

108 Gamis AS, Smith FO. Transient myeloproliferative disorder in children with Down syndrome: clarity to this enigmatic disorder. $\mathrm{Br} J$ Haematol 2012; 159: 277-287 
109 Viswanathan SR, Powers JT, Einhorn W, Hoshida Y, Ng TL, Toffanin S et al. Lin28 promotes transformation and is associated with advanced human malignancies. Nat Genet 2009; 41: 843-U109.

110 Fusco A, Fedele M. Roles of HMGA proteins in cancer. Nat Rev Cancer 2007; 7: 899-910.

111 Boyerinas B, Park SM, Hau A, Murmann AE, Peter ME. The role of let-7 in cell differentiation and cancer. Endocr-Relat cancer 2010; 17: F19-F36.

112 Li Z, Zhang Y, Ramanujan K, Ma Y, Kirsch DG, Glass DJ. Oncogenic NRAS, required for pathogenesis of embryonic rhabdomyosarcoma, relies upon the HMGA2-IGF2BP2 pathway. Cancer Res 2013; 73: 3041-3050.

113 Copelan EA. Hematopoietic stem-cell transplantation. New Engl J Med 2006; 354: 1813-1826.

114 Takizawa H, Schanz U, Manz MG. Ex vivo expansion of hematopoietic stem cells: mission accomplished? Swiss Med Wkly 2011; 141: w13316.

115 Kardel MD, Eaves CJ. Modeling human hematopoietic cell development from pluripotent stem cells. Exp Hematol 2012; 40: 601-611.

116 Broxmeyer HE, Cooper S, Hass DM, Hathaway JK, Stehman FB, Hangoc G. Experimental basis of cord blood transplantation. Bone Marrow Transplant 2009; 44: 627-633.

117 Wang GP, Berry CC, Malani N, Leboulch P, Fischer A, Hacein-Bey-Abina $S$ et al. Dynamics of gene-modified progenitor cells analyzed by tracking retroviral integration sites in a human SCID-X1 gene therapy trial. Blood 2010; 115: 4356-4366.
118 Cavazzana-Calvo M, Payen E, Negre O, Wang G, Hehir K, Fusil F et al. Transfusion independence and HMGA2 activation after gene therapy of human beta-thalassaemia. Nature 2010; 467: 318-322.

119 Li Z, Gilbert JA, Zhang Y, Zhang M, Qiu Q, Ramanujan K et al. An HMGA2-IGF2BP2 axis regulates myoblast proliferation and myogenesis. Dev Cell 2012; 23: 1176-1188.

120 Nishino J, Kim I, Chada K, Morrison SJ. Hmga2 promotes neural stem cell self-renewal in young but not old mice by reducing p16Ink4a and p19Arf expression. Cell 2008; 135: 227-239.

121 Kruger GM, Mosher JT, Bixby S, Joseph N, Iwashita T, Morrison SJ. Neural crest stem cells persist in the adult gut but undergo changes in self-renewal, neuronal subtype potential, and factor responsiveness. Neuron 2002; 35: 657-669.

122 Toledano H, D'Alterio C, Czech B, Levine E, Jones DL. The let-7-Imp axis regulates ageing of the Drosophila testis stem-cell niche. Nature 2012; 485: 605-610.

(c) (i) $(9)$ This work is licensed under a Creative Commons Attribution-NonCommercial-NoDerivs 3.0 Unported License. To view a copy of this license, visit http:// creativecommons.org/licenses/by-nc-nd/3.0/ 